\title{
Socio-economic differences in weight-control behaviours and barriers to weight control
}

\author{
Jessica Siu*, Katrina Giskes and Gavin Turrell \\ School of Public Health, Institute of Health and Biomedical Innovation, Queensland University of Technology, \\ Victoria Park Road, Kelvin Grove, Queensland 4059, Australia
}

Submitted 15 September 2010: Accepted 20 February 2011: First published online 4 May 2011

\begin{abstract}
Objective: To examine socio-economic differences in weight-control behaviours (WCB) and barriers to weight control.

Design: A cross-sectional study.

Setting: Data were obtained by means of a postal questionnaire.

Subjects: A total of 1013 men and women aged 45-60 years residing in Brisbane, Australia (69.8\% response rate).

Results: Binary and multinomial logistic regression analyses were performed, adjusted for age, gender and BMI. Socio-economically disadvantaged groups were less likely to engage in weight control (OR for lowest income quartile = $0 \cdot 60$, 95\% CI 0.39, 0.94); among those who engaged in weight control, the disadvantaged group had a likelihood of $0.52(95 \%$ CI $0.30,0.90)$ of adopting exercise strategies, including moderate $(\mathrm{OR}=0 \cdot 56,95 \% \mathrm{CI} 0 \cdot 33,0 \cdot 96)$ and vigorous $(\mathrm{OR}=0 \cdot 47,95 \% \mathrm{CI} 0 \cdot 25,0 \cdot 89)$ physical activities, compared with their more-advantaged counterparts. However, lower socio-economic groups were more likely to decrease their sitting time to control their weight compared with their advantaged counterparts (OR for secondary school or lower education $=$ $1 \cdot 78,95 \%$ CI $1 \cdot 11,2 \cdot 84)$. They were also more likely to believe that losing weight was expensive, not of high priority, required a lot of cooking skills and involved eating differently from others in the household.

Conclusions: Marked socio-economic inequalities existed with regard to engaging in WCB, the type of weight-control strategies used and the perceived barriers to weight control; these differences are consistent with socio-economic gradients in weight status. These factors may need to be included in health promotion strategies that address socio-economic inequalities in weight status, as well as inequalities in weight-related health outcomes.
\end{abstract}

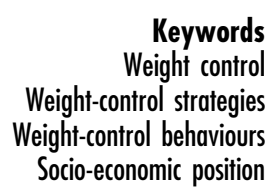

Keywords Weight-control strategies Socio-economic position
Overweight and obesity have increased markedly over the past two decades in developed countries ${ }^{(1,2)}$ and this increase is predicted to continue ${ }^{(3)}$. A large body of literature shows that socio-economically disadvantaged groups experience a greater prevalence of overweight or obesity compared with their more-advantaged counterparts, and in developed countries this association has been observed more consistently among women ${ }^{(4,5)}$. Inequalities in overweight or obesity are considered a major contributing factor to the higher morbidity and mortality accruing from chronic conditions such as CVD, type 2 diabetes and some cancers seen among lower socio-economic groups ${ }^{(6)}$. Although there is extensive literature documenting socio-economic inequalities in overweight or obesity, relatively less is known about the factors contributing to this relationship ${ }^{(7)}$.

Weight-control behaviours (WCB) are behaviours adopted by individuals to intentionally reduce their weight or prevent weight gain ${ }^{(8)}$. Some studies show that higher socio-economic groups weigh themselves more frequently ${ }^{(9,10)}$, have a greater prevalence of weight-loss intentions $^{(11)}$ and report current ${ }^{(12)}$ and past weightcontrol $^{(13)}$ measures more frequently. On the other hand, studies have shown inconsistent associations between WCB and socio-economic position (SEP) ${ }^{(14,15)}$. Although few studies have examined socio-economic differences in WCB, there are even fewer studies ${ }^{(9,11,16)}$ that have examined the types of weight-control strategies used by different socio-economic groups. These studies are limited in a number of ways. Some were published over a decade ago ${ }^{(9,11)}$, or were conducted among a population subgroup (e.g. women aged $20-45$ years) ${ }^{(9)}$ or have been limited in examining some WCB in detail (e.g. have combined exercise strategies such as moderate physical activity, vigorous physical activity and walking, rather than examining them separately $)^{(9,11,16)}$. Despite the 
limitations, these studies suggest that higher socio-economic groups are more likely to reduce their food or energy intakes $^{(9,11)}$, increase their level of exercise ${ }^{(9,16)}$ and use commercial weight-loss programmes ${ }^{(16)}$ or meal replacements $^{(16)}$, compared with their lower socio-economic counterparts.

Socio-economic differences in WCB may also be due to differences in the perceived barriers that these groups have towards weight control. To our knowledge, there are no known population-based studies that have examined socio-economic differences in barriers to weight control. However, a number of studies have examined barriers to weight-control programmes among population subgroups and have found that programme cost, availability of childcare, lack of time, family commitments and conflict with work schedules were barriers perceived by low-income women for attending weight-control programmes $^{(17)}$. Furthermore, some studies have examined barriers to healthy dietary intakes and physical activity. The cost and availability of healthy foods ${ }^{(18,19)}$, lack of time because of work commitments ${ }^{(19)}$ and inconvenience of access to facilities ${ }^{(20)}$ have been suggested as possible barriers to healthy dietary behaviours and physical activity that vary between socio-economic groups.

Understanding and addressing the WCB of socioeconomically disadvantaged groups may be important for clinical and public health interventions in order to decrease overweight or obesity and their health consequences among these groups. The present study addresses this by examining socio-economic differences in WCB among a population representative sample of middle-aged adults. Middle-aged adults experience the greatest prevalence of overweight and obesity ${ }^{(21)}$. Furthermore, among this age group, weight status is less influenced by growth, development or ageing ${ }^{(22)}$ and SEP is generally more established compared with younger age groups ${ }^{(23)}$.

\section{Methods}

\section{Participants}

A sample of 1500 middle-aged Australian citizens residing in Brisbane city (Australia) were selected by simple random sampling from the electoral roll in 2009. The electoral roll is Australia's most comprehensive population registrar (voting is compulsory for all adults aged $\geq 18$ years) and has almost complete coverage (95\%) of the age group selected in the present study ${ }^{(24)}$. The present study was approved by the Queensland University of Technology Human Research Ethics Committee in Brisbane, Australia.

\section{Data collection}

A self-administered postal questionnaire collected information on the participants' demographic characteristics, SEP, weight status, WCB and barriers to weight control. The mail survey method recommended by Dillman ${ }^{(25)}$, involving three to five items of correspondence sent to selected individuals, was used to maximise the study response rate. This included, among other things, a prenotification letter, a reply-paid envelope and a small gratuity (i.e. one-dollar scratch-it ticket) with the questionnaire, reminder mails to encourage non-responders to return the questionnaire, a cover letter and logo on the questionnaire informing the participants that the study was sponsored by a university and a personalised salutation on all correspondence $^{(26-28)}$. The final response rate was $69 \cdot 8 \%$ (1013 of 1452) after excluding refusals, non-respondents, those who could not be reached (e.g. questionnaires returned to sender) and those who were unable to fill out the questionnaire (e.g. because of illness or cognitive impairment).

\section{Test-retest reliability study}

To test the reliability of several new measures in the survey, a separate sample of 100 participants was asked to complete the questionnaire twice, 2 weeks apart ( $47 \cdot 0 \%$ response rate for return of both surveys). The same sampling method and mail-out procedure used in the main study were used. The $\kappa$ coefficient and crude agreement were calculated for weight control in the past 12 months, as well as for weight-control strategies and barriers to weight control. The benchmarks used to assess the strength of reliability were based on values proposed by Landis and $\mathrm{Koch}^{(29)}$, where $\kappa \leq 0 \cdot 00$ is considered poor, $0 \cdot 00-0 \cdot 20$ is slight, $0 \cdot 21-0 \cdot 40$ is fair, $0 \cdot 41-0 \cdot 60$ is moderate, $0 \cdot 61-0 \cdot 80$ is substantial and $0 \cdot 81-1 \cdot 00$ is almost perfect reliability.

\section{Measures}

\section{Weight status and BMI}

BMI was calculated using the Quetelet index (weight in kilograms divided by the square of height in metres $\left(\mathrm{kg} / \mathrm{m}^{2}\right)$ ). Self-reported height and weight were ascertained by the following questions: 'How tall are you without shoes on? (Please tell us in either centimetres, or feet and inches)' and 'How much do you weigh without your clothes and shoes? (Please tell us in either kilograms, or stone and pounds)'. BMI was then categorised into the National Health and Medical Research Council weight status categories of underweight $\left(<18.5 \mathrm{~kg} / \mathrm{m}^{2}\right)$, normal weight $\left(18 \cdot 5-24 \cdot 9 \mathrm{~kg} / \mathrm{m}^{2}\right)$, overweight $\left(25 \cdot 0-29 \cdot 9 \mathrm{~kg} / \mathrm{m}^{2}\right)$ and obese $\left(\geq 30 \cdot 0 \mathrm{~kg} / \mathrm{m}^{2}\right)^{(30)}$.

\section{Weight-control behaviours}

Weight control in the past 12 months. Weight control in the past 12 months was ascertained by means of a modified question used in the Australian Diabetes, Obesity and Lifestyle Study ${ }^{(31)}$. Participants were asked: 'Which of the following best describes your situation within the past 12 months?'. Response options were: I have been doing things to 'Try to gain weight', 'Avoid weight gain', 'Try to lose weight'; and 'I have not done anything about my weight'. These response options were re-categorised into 
two groups for analyses: 'Tried to lose weight or avoid weight gain' and 'Did not engage in weight control or tried to gain weight'. The $\kappa$ coefficient was 0.95 and crude agreement was $0 \cdot 98$, indicating an almost perfect agreement.

Weight-control strategies. Participants who engaged in weight control were subsequently asked about their engagement in a range of weight-control strategies. The question asked was: 'In the past 12 months, have you done any of the following to lose weight or avoid gaining weight?'. A list of twenty-seven specific weight-control strategies, adopted from items from the Australian Longitudinal Study of Women's Health ${ }^{(8)}$ and National Health and Nutrition Examination Survey ${ }^{(32)}$, was provided (as presented in Table 2) and participants were asked in a yes/no format whether they were engaged in any of the strategies. The $\kappa$ coefficient for weight-control strategies ranged from -0.04 to $1 \cdot 00$. It has been suggested that $\kappa$ coefficients should be interpreted with caution when the prevalence of an outcome is low ${ }^{(33,34)}$. Weight-control strategies with $\kappa$ coefficients (see Table 2 ) $<0 \cdot 41$ had high crude agreements, except for moderate physical activity, indicating that the reliability of this strategy was fair.

\section{Barriers to weight control}

This item was adopted from previous studies (including qualitative and quantitative studies) exploring socioeconomic differences in barriers to healthy dietary intakes and physical activity ${ }^{(18-20)}$. All participants were asked to rate their agreement on statements about fourteen barriers to weight control on a 4-point Likert scale, from 'Strongly agree' to 'Strongly disagree' or 'Don't know' (as presented in Table 4). Participants were asked: 'How much do you agree or disagree with each statement?' The majority of perceived barriers to weight control had a moderate-to-perfect reliability (see Table 4), except for 'Requires support from other people around' $(\boldsymbol{\kappa}=0.39)$ and 'Not difficult at all' $(\boldsymbol{\kappa}=0 \cdot 29)$; however, these two perceived barriers had a high crude agreement of 0.69 and 0.76 , respectively. This suggests that these barriers are substantially reliable.

\section{Socio-economic position}

The highest educational qualification and equivalised household income were considered to be the most appropriate socio-economic indicators for the present study. Education reflects the potential knowledge that participants may have about recommended dietary intakes, physical activity and healthy weight ranges ${ }^{(35)}$. Income reflects the access to resources, such as money to purchase food or special dietary or weight-loss products, and/or pays for access to some organised physical activity or physical activity infrastructure ${ }^{(36,37)}$.

Education. Education was ascertained by the following question: 'What is the highest educational qualification you have completed?' Response options were: (1) year 9 or less,
(2) year 10 (junior/4th form), (3) year 11 (senior/5th form), (4) year 12 (senior/6th form), (5) certificate (trade or business), (6) diploma or associated degree, (7) Bachelor's degree (pass or honours), (8) graduate diploma or graduate certificate and (9) postgraduate degree (Master's degree or doctorate). These response categories were re-grouped into four educational levels for analyses: (i) secondary-school qualification or lower (response options 1-4), (ii) certificate (option 5), (iii) diploma (option 6) and (iv) Bachelor's degree or higher (options 7-9).

Equivalised housebold income. Household income was ascertained by the question: 'Please add up the amount of before-tax income received by all members of your household and tick the box that comes closest to this number'. Participants had the option to select from the eleven income categories (their income per year, per fortnight or per week), or the option 'Don't know' or 'Don't want to answer this'. Household income was used to calculate equivalised household income, an adjusted income measure that takes into account the different size and composition of households ${ }^{(38)}$. Equivalised household income was calculated by dividing household income (the mid-point of the income range per year) by equivalised income units. Equivalised income units were determined by summing the number of people in the household, whereby the first person in the household was assigned a weight of $1 \cdot 0$, and subsequent adults ( $\geq 18$ years of age) and children ( $\leq 17$ years of age) were assigned weights of 0.5 and $0 \cdot 3$, respectively. This method has been adopted from the Australian Bureau of Statistics ${ }^{(38)}$. Equivalised household income was then divided into quartiles: '<\$AUD27 130•1/year', '\$AUD27 130•1\$AUD43333·0/year', '\$AUD43333·1-\$AUD61 904·8/year' and '>\$AUD61 904·8/year'.

\footnotetext{
Analyses

The $\chi^{2}$ test was used to compare the sociodemographic characteristics of men and women in the sample. Statistical comparison was not made between the sociodemographic distribution of the sample and the Brisbane census data, as the census data were not independent of the sample and the large cell sizes in the census data would have made minor differences statistically significant. Instead, comparisons between the distribution of the study sample and census data were made and meaningful deviations in their distributions were noted. All multivariate analyses were adjusted for gender, country of birth and BMI. Exploratory analyses of the data confirmed that the magnitude of associations examined was different for men and women; however, the direction of associations was the same. Hence, rather than stratify by gender, analyses were adjusted for gender differences to offer greater statistical power. Country of birth was adjusted for in the analyses as it was associated with SEP and weight control in the past 12 months. It was ascertained by the following open question: 'In which
} 
country were you born?' Responses were categorised as 'Australia or New Zealand', 'UK' and 'Other country'.

Participants with missing data on their country of birth, BMI, education, income and WCB in the past 12 months were excluded from the analyses ( $n$ 87, 8.6\%); the remaining analytical sample comprised 926 participants. Analyses examining differences in weight-control strategies and barriers to weight control consisted of different analytical sample sizes because of varying numbers of participants with missing data.

Binary logistic regression was used to examine socioeconomic differences in WCB, and multinomial logistic regression was used to examine socio-economic differences in barriers to weight control. Only socio-economic differences in more prevalent weight-control strategies (i.e. strategies engaged by $>20 \%$ of the sample) were examined. Analyses were conducted using the Statistical Package for the Social Sciences statistical software package version $17 \cdot 0$ (SPSS Inc., Chicago, IL, USA). Differences were considered statistically significant if $P \leq 0.05$ (two-tailed) or if the confidence interval of the OR was exclusive of 1 .

\section{Results}

\section{Participants}

Table 1 shows that older participants and those with a Bachelor's degree or higher were over-represented in the current sample, in comparison with the 2006 Census data for the study region ${ }^{(39)}$. A higher proportion of women were within the healthy weight range. Women had a marginally lower BMI than men. However, men were less likely to have tried to lose or maintain their weight in the past 12 months compared with women. The majority of

Table 1 Sociodemographic characteristics of the study sample compared with the Brisbane population

\begin{tabular}{|c|c|c|c|c|}
\hline & \multicolumn{2}{|c|}{$\begin{array}{l}\text { Current study } \\
\qquad\left(n 926^{*}\right)\end{array}$} & \multicolumn{2}{|c|}{$\begin{array}{l}\text { Brisbane population in the } 2006 \\
\text { Census ( } n \text { 240 394) }\end{array}$} \\
\hline & Men $(46 \cdot 0 \%)$ & Women $(54 \cdot 0 \%)$ & Men $(49 \cdot 0 \%)$ & Women $(51 \cdot 0 \%)$ \\
\hline & $\%$ & $\%$ & $\%$ & $\%$ \\
\hline \multicolumn{5}{|l|}{ Age (years) } \\
\hline $45-49$ & $30 \cdot 3$ & $25 \cdot 4$ & $34 \cdot 0$ & $34 \cdot 7$ \\
\hline $50-54$ & $28 \cdot 9$ & $32 \cdot 4$ & $31 \cdot 4$ & $31 \cdot 6$ \\
\hline $55-60$ & $40 \cdot 8$ & $42 \cdot 2$ & $34 \cdot 6$ & $33 \cdot 7$ \\
\hline$P$ value & & 0.22 & & - \\
\hline \multicolumn{5}{|l|}{ Country of birth } \\
\hline Oceania & $75 \cdot 6$ & $76 \cdot 4$ & $73 \cdot 4$ & $74 \cdot 2$ \\
\hline Other countries & $24 \cdot 4$ & $23 \cdot 6$ & $26 \cdot 6$ & $25 \cdot 8$ \\
\hline$P$ value & & 0.89 & & - \\
\hline \multicolumn{5}{|l|}{ Educational level } \\
\hline Secondary school or lower & $37 \cdot 6$ & $48 \cdot 2$ & $38 \cdot 8$ & $54 \cdot 7$ \\
\hline Certificate & $17 \cdot 8$ & $16 \cdot 2$ & $26 \cdot 4$ & $10 \cdot 8$ \\
\hline Diploma & $14 \cdot 6$ & $10 \cdot 2$ & $9 \cdot 4$ & $10 \cdot 8$ \\
\hline Bachelor's or higher & $30 \cdot 0$ & $25 \cdot 4$ & $25 \cdot 4$ & $23 \cdot 7$ \\
\hline$P$ value & & $<0.01$ & & - \\
\hline \multicolumn{5}{|l|}{ Equivalised household income (quartiles) $\dagger$} \\
\hline 1st & $19 \cdot 2$ & $20 \cdot 6$ & $-\S$ & $-\S$ \\
\hline 2nd & $23 \cdot 2$ & $21 \cdot 8$ & $-\S$ & $-\S$ \\
\hline 3rd & $26 \cdot 3$ & $23 \cdot 0$ & $-\S$ & $-\S$ \\
\hline 4th & $23 \cdot 9$ & $19 \cdot 2$ & $-\S$ & $-\S$ \\
\hline$P$ value & & $<0.01$ & & \\
\hline \multicolumn{5}{|l|}{ Weight status $\ddagger$} \\
\hline Underweight & $0 \cdot 2$ & $1 \cdot 8$ & $-\S$ & $-\S$ \\
\hline Healthy weight & $25 \cdot 4$ & $43 \cdot 8$ & $-\S$ & $-\S$ \\
\hline Overweight & $50 \cdot 0$ & $27 \cdot 0$ & $-\S$ & $-\S$ \\
\hline Obese & $24 \cdot 4$ & $27 \cdot 4$ & $-\S$ & $-\S$ \\
\hline$P$ value & & $<0 \cdot 01$ & & \\
\hline \multicolumn{5}{|l|}{ BMI $\left(\mathrm{kg} / \mathrm{m}^{2}\right)$} \\
\hline Mean & $27 \cdot 8$ & $27 \cdot 1$ & $-\S$ & $-\S$ \\
\hline $\begin{array}{l}\mathrm{SD} \\
P \text { value }\end{array}$ & $4 \cdot 5$ & $\begin{array}{l}6 \cdot 3 \\
0.06\end{array}$ & $-\S$ & $-\S$ \\
\hline \multicolumn{5}{|l|}{ Weight control in the past 12 months } \\
\hline Tried to lose weight or avoid weight gain & $60 \cdot 6$ & $69 \cdot 4$ & $-\S$ & $-\S$ \\
\hline $\begin{array}{l}\text { Did not engage in weight control measures } \\
\text { or tried to gain weight }\end{array}$ & $39 \cdot 4$ & $30 \cdot 6$ & $-\S$ & $-\S$ \\
\hline$P$ value & & $<0.01$ & & \\
\hline
\end{tabular}

*The analytical sample excludes those with missing data for country of birth, BMI, education, income and weight-control behaviours in the past 12 months. tParticipants who responded 'Don't know' or 'Don't want to answer' were included in the analyses; however, results are not shown in the current table. $\ddagger$ Weight status was categorised into the National Health and Medical Research Council categories of underweight $\left(<18.5 \mathrm{~kg} / \mathrm{m}^{2}\right), \mathrm{normal} \mathrm{weight}\left(18 \cdot 5-24 \cdot 9 \mathrm{~kg} / \mathrm{m}^{2}\right)$, overweight $\left(25 \cdot 0-29 \cdot 9 \mathrm{~kg} / \mathrm{m}^{2}\right)$ and obese $\left(\geq 30 \cdot 0 \mathrm{~kg} / \mathrm{m}^{2}\right)^{(40)}$.

§Categories were not comparable to those used in the 2006 Census. 
Table 2 The prevalence of weight-control strategies adopted in the past 12 months and test-retest reliability*

\begin{tabular}{|c|c|c|c|c|c|}
\hline Weight-control strategies adopted & $n$ & Frequency & $\%$ & $\kappa$ coefficient & Crude agreement \\
\hline Reduced the amount of junk food and/or snacks & 594 & 470 & $79 \cdot 1$ & $0 \cdot 14$ & $0 \cdot 80$ \\
\hline Decreased fat intake & 590 & 450 & $76 \cdot 3$ & $0 \cdot 84$ & 0.97 \\
\hline Increased fruit and/or vegetable intake & 591 & 419 & $70 \cdot 9$ & $0 \cdot 42$ & $0 \cdot 76$ \\
\hline Reduced the amount of food eaten & 585 & 406 & $69 \cdot 4$ & 0.63 & 0.93 \\
\hline Increased the level of exercise & 592 & 403 & $68 \cdot 1$ & $0 \cdot 79$ & 0.93 \\
\hline Increased walking & 593 & 395 & $66 \cdot 6$ & 0.59 & $0 \cdot 83$ \\
\hline Ate fewer carbohydrates or sugar & 589 & 386 & $65 \cdot 5$ & $0 \cdot 36$ & $0 \cdot 74$ \\
\hline Switched to foods with lower energy & 585 & 300 & $51 \cdot 3$ & 0.67 & 0.85 \\
\hline Engaged in moderate physical activity & 587 & 254 & $43 \cdot 3$ & $0 \cdot 34$ & $0 \cdot 30$ \\
\hline Drank less alcohol & 590 & 230 & $39 \cdot 0$ & $0 \cdot 40$ & $0 \cdot 70$ \\
\hline Engaged in vigorous physical activity & 586 & 166 & $28 \cdot 3$ & 0.67 & 0.85 \\
\hline Decreased time spent sitting & 589 & 160 & $27 \cdot 2$ & $0 \cdot 36$ & $0 \cdot 78$ \\
\hline Skipped meals & 590 & 114 & $19 \cdot 3$ & $0 \cdot 79$ & 0.93 \\
\hline Consumed liquid diet supplement(s) or meal replacements & 592 & 95 & $16 \cdot 0$ & 0.46 & 0.93 \\
\hline Joined a commercial weight loss programme & 593 & 74 & $12 \cdot 5$ & -0.04 & 0.93 \\
\hline Followed a special diet & 593 & 64 & $10 \cdot 8$ & $0 \cdot 71$ & 0.93 \\
\hline Visited a general practitioner & 593 & 63 & $10 \cdot 6$ & $1 \cdot 00$ & $1 \cdot 00$ \\
\hline Visited a personal trainer or exercise physiologist & 594 & 53 & 8.9 & 0.51 & $0 \cdot 89$ \\
\hline Visited a dietitian or nutritionist & 593 & 42 & $7 \cdot 1$ & $0 \cdot 76$ & 0.93 \\
\hline Used detox products or followed a detox programme & 593 & 23 & $3 \cdot 9$ & 0.65 & 0.97 \\
\hline Visited a naturopath & 593 & 21 & $3 \cdot 5$ & $-\dagger$ & $1 \cdot 00$ \\
\hline Fasted & 600 & 15 & $2 \cdot 5$ & $-\dagger$ & 1.00 \\
\hline Used appetite suppressants or diet pills & 601 & 15 & $2 \cdot 5$ & $-\dagger$ & $1 \cdot 00$ \\
\hline Used laxatives & 601 & 13 & $2 \cdot 2$ & -+ & $1 \cdot 00$ \\
\hline Started to smoke or smoked more & 593 & 13 & $2 \cdot 0$ & $-\dagger$ & $1 \cdot 00$ \\
\hline Used diuretics & 602 & 7 & $1 \cdot 2$ & $1 \cdot 00$ & $1 \cdot 00$ \\
\hline Vomited & 600 & 4 & 0.7 & $-\dagger$ & 1.00 \\
\hline
\end{tabular}

*Only participants who reported weight control in the past 12 months are included in this table. The analytical sample excludes those with missing data for country of birth, BMI, education, income and weight-control strategies.

tUnable to calculate $\kappa$ coefficient because of perfect agreement between the two questionnaires.

men $(60 \cdot 6 \%)$ and women $(69 \cdot 4 \%)$ reported engaging in weight control in the past 12 months.

\section{Weight-control strategies}

In Table 2, weight-control strategies adopted by the sample are listed in the order from the most to the least prevalent. Participants who did not engage in weight control or were trying to gain weight were excluded in this table. The more common weight-control strategies were dietary modification and exercise strategies (up to $80 \%$ ), whereas visiting health professionals (4-11\%) for weight-control advice and the use of appetite suppressants or diet pills $(2 \cdot 5 \%)$, laxatives $(2 \cdot 2 \%)$, diuretics $(1 \cdot 2 \%)$, fasting $(2 \cdot 5 \%)$, vomiting $(0.7 \%)$ and smoking $(2 \cdot 0 \%)$ were less prevalent strategies.

\section{Socio-economic differences in weight status and weight-control strategies}

Table 3 shows that participants with lower educational levels and lower household incomes were more likely to be obese and less likely to engage in weight-control activities to lose weight or avoid weight gain compared with their more-advantaged counterparts.

Socio-economically disadvantaged groups were less likely to increase their level of exercise (income only) or engage in vigorous or moderate (income only) physical activity compared with their socio-economically advantaged counterparts. The disadvantaged group was also more likely to report decreasing time spent sitting as a strategy for weight control. No socio-economic differences were observed in other weight-control strategies.

\section{Barriers to weight control}

Table 4 shows that over half of the participants agreed that trying to lose weight required serious commitment (87·7\%), required considerable motivation $(84 \cdot 1 \%)$, was difficult $(69 \cdot 0 \%)$, required support from their partner $(63 \cdot 3 \%)$, required a lot of food and exercise knowledge $(56 \cdot 1 \%)$, was difficult to achieve when they were dining out $(55 \cdot 5 \%)$, was not of high priority $(54 \cdot 0 \%)$, was time-consuming $(51 \cdot 8 \%)$ and required support from other people around oneself $(50 \cdot 2 \%)$. Less-prevalent beliefs about weight control were that it was restrictive $(47 \cdot 7 \%)$, required eating differently from other people in the household (42.7\%), was expensive (29.5\%), was not difficult at all (22.6\%) and required a lot of cooking skills $(21 \cdot 2 \%)$.

\section{Socio-economic differences in barriers to weight control}

Barriers to weight control by education and income are summarised in Table 5. There were some socio-economic differences in barriers to weight control. Participants with secondary-school or lower education were more likely to perceive that weight control was expensive and required a lot of cooking skills, whereas those within the lowest income quartile were more likely to perceive 
Table 3 The OR and $95 \% \mathrm{Cl}$ for socio-economic differences in weight status and weight-control strategies*

\begin{tabular}{|c|c|c|c|c|c|c|c|}
\hline & \multicolumn{7}{|c|}{ Educational level } \\
\hline & \multicolumn{2}{|c|}{ Secondary school or lower } & \multicolumn{2}{|c|}{ Certificate } & \multicolumn{2}{|c|}{ Diploma } & \multirow{2}{*}{$\begin{array}{l}\text { Bachelor's degree } \\
\text { or higher (ref.) }\end{array}$} \\
\hline & OR & $95 \% \mathrm{Cl}$ & OR & $95 \% \mathrm{Cl}$ & OR & $95 \% \mathrm{Cl}$ & \\
\hline \multicolumn{8}{|l|}{ Weight statust } \\
\hline Healthy weight & 0.49 & $0.32,0.76$ & 0.39 & $0.22,0.69$ & 0.44 & $0.24,0.82$ & $1 \cdot 00$ \\
\hline Overweight & $1 \cdot 07$ & $0 \cdot 71,1 \cdot 61$ & $1 \cdot 19$ & $0.71,1.97$ & $1 \cdot 31$ & $0 \cdot 76,2 \cdot 25$ & 1.00 \\
\hline Obese & 2.00 & $1 \cdot 29,3 \cdot 12$ & 1.64 & $0.95,2.85$ & 1.75 & $0.97,3 \cdot 14$ & 1.00 \\
\hline \multicolumn{8}{|l|}{ Weight control in the past 12 monthsł } \\
\hline Tried to lose weight or avoid weight gain & 0.50 & $0.35,0.71$ & 0.54 & $0.35,0.84$ & 0.99 & $0.59,1.66$ & 1.00 \\
\hline \multicolumn{8}{|l|}{ Weight-control strategies $\$$} \\
\hline Reduced the amount of junk food and/or snacks & 0.96 & $0.59,1.54$ & 1.86 & $0.92,3.76$ & 0.78 & $0.42,1 \cdot 46$ & 1.00 \\
\hline Decreased fat intake & 0.94 & $0.59,1.49$ & 1.28 & $0 \cdot 69,2 \cdot 36$ & $1 \cdot 13$ & $0 \cdot 59,2 \cdot 15$ & 1.00 \\
\hline Increased fruit and/or vegetable intake & 0.85 & $0.55,1 \cdot 31$ & 1.39 & $0 \cdot 77,2 \cdot 50$ & 0.97 & $0.54,1 \cdot 76$ & $1 \cdot 00$ \\
\hline Reduced the amount of food eaten & 0.73 & $0 \cdot 47,1 \cdot 14$ & 1.67 & $0.90,3.11$ & 0.79 & $0.44,1.44$ & 1.00 \\
\hline Increased the level of exercise & 0.77 & $0.50,1 \cdot 20$ & 0.72 & $0.42,1 \cdot 24$ & 0.75 & $0.42,1.33$ & 1.00 \\
\hline Increased walking & $1 \cdot 18$ & $0.77,1.79$ & 1.03 & $0.61,1 \cdot 74$ & $1 \cdot 10$ & $0.62,1.94$ & 1.00 \\
\hline Ate fewer carbohydrates or sugar & 0.96 & $0.63,1 \cdot 46$ & $1 \cdot 18$ & $0.68,2.03$ & 1.54 & $0.84,2 \cdot 81$ & 1.00 \\
\hline Switched to foods with lower energy & $1 \cdot 13$ & $0 \cdot 75,1 \cdot 70$ & 1.83 & $1.09,3.08$ & $1 \cdot 22$ & $0 \cdot 70,2 \cdot 11$ & 1.00 \\
\hline Engaged in moderate physical activity & 0.79 & $0.53,1 \cdot 18$ & 0.88 & $0.53,1.46$ & 0.87 & $0.51,1.50$ & 1.00 \\
\hline Drank less alcohol & 0.89 & $0.59,1.34$ & 0.98 & $0.59,1.64$ & 1.06 & $0.61,1.84$ & 1.00 \\
\hline Engaged in vigorous physical activity & 0.50 & $0.32,0.78$ & 0.55 & $0.31,0.99$ & 0.92 & $0.52,1.65$ & 1.00 \\
\hline \multirow[t]{4}{*}{ Decreased time spent sitting } & $1 \cdot 78$ & $1 \cdot 11,2 \cdot 84$ & 1.60 & $0.89,2.86$ & $1 \cdot 22$ & $0.64,2.33$ & 1.00 \\
\hline & \multicolumn{7}{|c|}{ Equivalised household income\|l } \\
\hline & \multicolumn{2}{|c|}{ 1st quartile } & \multicolumn{2}{|c|}{ 2nd quartile } & \multicolumn{2}{|c|}{ 3rd quartile } & \\
\hline & OR & $95 \% \mathrm{Cl}$ & OR & $95 \% \mathrm{Cl}$ & OR & $95 \% \mathrm{Cl}$ & 4th quartile (ref.) \\
\hline \multicolumn{8}{|l|}{ Weight statust } \\
\hline Healthy weight & 0.69 & $0 \cdot 38,1 \cdot 24$ & 1.02 & $0.60,1 \cdot 75$ & 0.89 & $0.53,1.50$ & 1.00 \\
\hline Overweight & 0.58 & $0.34,0.98$ & 0.73 & $0.45,1.21$ & 0.82 & $0.51,1.30$ & 1.00 \\
\hline Obese & $2 \cdot 11$ & $1 \cdot 22,3.67$ & $1 \cdot 21$ & $0 \cdot 70,2 \cdot 07$ & 1.39 & $0.83,2 \cdot 30$ & 1.00 \\
\hline \multicolumn{8}{|l|}{ Weight control in the past 12 months $\ddagger$} \\
\hline Tried to lose weight or avoid weight gain & 0.60 & $0.39,0.94$ & 0.68 & $0.44,1.05$ & 1.05 & $0.68,1.62$ & 1.00 \\
\hline \multicolumn{8}{|l|}{ Weight-control strategies§ } \\
\hline Reduced the amount of junk foods and/or snacks & $0 \cdot 76$ & $0.41,1 \cdot 44$ & 0.71 & $0 \cdot 40,1 \cdot 27$ & $1 \cdot 19$ & $0 \cdot 66,2 \cdot 14$ & 1.00 \\
\hline Decreased fat intake & $1 \cdot 49$ & $0 \cdot 78,2 \cdot 87$ & 0.81 & $0.47,1.42$ & $1 \cdot 28$ & $0 \cdot 74,2 \cdot 20$ & 1.00 \\
\hline Increased fruit and/or vegetable intake & 0.76 & $0 \cdot 43,1 \cdot 34$ & 0.74 & $0 \cdot 44,1 \cdot 26$ & $1 \cdot 15$ & $0.69,1.94$ & 1.00 \\
\hline Reduced the amount of food eaten & 0.97 & $0.54,1.74$ & 0.73 & $0.43,1.24$ & $1 \cdot 21$ & $0.72,2.04$ & 1.00 \\
\hline Increased the level of exercise & 0.52 & $0.30,0.90$ & 0.82 & $0.48,1 \cdot 40$ & 0.85 & $0.51,1 \cdot 41$ & 1.00 \\
\hline Increased walking & 0.84 & $0.49,1.46$ & 1.00 & $0.59,1.68$ & 0.95 & $0.58,1.55$ & 1.00 \\
\hline Ate fewer carbohydrates or sugar & 0.93 & $0.53,1.65$ & 0.76 & $0.45,1.29$ & 0.83 & $0.51,1.37$ & 1.00 \\
\hline Switched to foods with lower energy & 0.87 & $0.51,1.49$ & 0.72 & $0 \cdot 44,1 \cdot 19$ & $0 \cdot 70$ & $0 \cdot 43,1 \cdot 12$ & 1.00 \\
\hline Engaged in moderate physical activity & 0.56 & $0.33,0.96$ & 0.61 & $0.37,1.01$ & 0.77 & $0.49,1.23$ & 1.00 \\
\hline Drank less alcohol & 0.81 & $0 \cdot 47,1 \cdot 40$ & 0.77 & $0.46,1.29$ & $1 \cdot 24$ & $0.77,1.98$ & 1.00 \\
\hline Engaged in vigorous physical activity & 0.47 & $0.25,0.89$ & 0.62 & $0.36,1.09$ & 0.95 & $0.57,1.56$ & 1.00 \\
\hline Decreased time spent sitting & 1.67 & $0.94,2.94$ & 0.95 & $0.54,1.67$ & 0.68 & $0.39,1 \cdot 18$ & 1.00 \\
\hline
\end{tabular}

Ref., reference category.

*All logistic regression analyses were adjusted for gender, country of birth and BMI except for analyses on socio-economic differences in weight status, which were adjusted for gender and country of birth only. The analytical sample excludes those with missing data for country of birth, BMl, education, income and weight-control behaviours in the past 12 months. Bold values hold statistically significant association and italicised bold values are borderline significant.

tParticipants who were underweight or had missing weight status information have been included in the analyses; however, results are not shown in the table. Because of small cell count, OR for the 'underweight' group could not be generated.

$\ddagger$ The analytical sample consisted of $n 961$ participants. The reference group consisted of participants who 'Did not engage in weight-control or tried to gain weight'.

\$Weight-control strategies engaged in by $>20 \%$ of participants who adopted weight-control strategies are included in this table. The analytical sample size varied for each strategy; refer to Table 2 for sample size. ॥Participants who responded 'Don't know' or 'Don't want to answer' were included in the analyses; however, results are not shown in the current table. 
Table 4 The prevalence of perceived barriers to weight control and test-retest reliability

\begin{tabular}{|c|c|c|c|c|c|}
\hline Prevalence of 'strongly agree or agree' that trying to lose weight & $n$ & Frequency & $\%$ & $\kappa$ coefficient & Crude agreement \\
\hline Requires serious commitment & 911 & 799 & $87 \cdot 7$ & $0 \cdot 77$ & 0.95 \\
\hline Requires a lot of motivation & 910 & 765 & $84 \cdot 1$ & 0.85 & 0.95 \\
\hline Is difficult & 914 & 631 & $69 \cdot 0$ & $0 \cdot 76$ & 0.93 \\
\hline Requires support from my partner & 901 & 570 & $63 \cdot 3$ & 0.67 & 0.87 \\
\hline Requires a lot of food and exercise knowledge & 908 & 509 & $56 \cdot 1$ & 0.50 & $0 \cdot 76$ \\
\hline Is difficult to achieve when you are dining out & 907 & 503 & $55 \cdot 5$ & $0 \cdot 71$ & 0.85 \\
\hline Is not a high priority when I have other things to do & 905 & 489 & $54 \cdot 0$ & 0.53 & $0 \cdot 77$ \\
\hline Is time-consuming & 907 & 470 & $51 \cdot 8$ & $0 \cdot 70$ & 0.85 \\
\hline Requires support from other people around you & 906 & 455 & $50 \cdot 2$ & $0 \cdot 39$ & 0.69 \\
\hline Is restrictive & 906 & 432 & $47 \cdot 7$ & $0 \cdot 70$ & $0 \cdot 85$ \\
\hline Requires you to eat differently from people in your household & 910 & 389 & $42 \cdot 7$ & $0 \cdot 70$ & 0.85 \\
\hline Is expensive & 908 & 268 & $29 \cdot 5$ & $0 \cdot 70$ & $0 \cdot 88$ \\
\hline Is not difficult at all & 904 & 204 & $22 \cdot 6$ & 0.29 & 0.76 \\
\hline Requires a lot of cooking skills & 910 & 193 & $21 \cdot 2$ & $0 \cdot 75$ & 0.93 \\
\hline
\end{tabular}

that trying to lose weight was not of high priority, required them to eat differently from other people in the household and was expensive, compared with their more-advantaged counterparts. There were no socioeconomic differences in other barriers to weight control.

\section{Discussion}

The present study showed that there were marked socio-economic differences in WCB and in some perceived barriers to weight control. Lower socio-economic groups were less likely to engage in WCB; however, when they did, they were less likely to engage in exercise strategies, including moderate and vigorous physical activities, compared with their higher socio-economic counterparts. Lower socio-economic groups were more likely to perceive a number of barriers to engaging in WCB; compared with their more-advantaged counterparts they were more likely to believe that trying to lose weight was expensive, not of high priority, required a lot of cooking skills and involved eating differently from other people in the household. Socio-economic differences in weight control and barriers to WCB may contribute to the higher prevalence of overweight or obesity and morbidity or mortality from weightrelated causes seen among lower socio-economic groups.

\section{Weight-control strategies}

Similar to previous studies, we also found that dietary modification (e.g. decreasing fat and reducing the quantity of food or energy intakes) and exercise strategies were the most popular practices adopted ${ }^{(12)}$. However, the use of appetite suppressants or diet pills, laxatives, diuretics, fasting, vomiting and smoking were less prevalent ${ }^{(12,13,40)}$. This may be because of a number of factors. Similar to international guidelines ${ }^{(41)}$, Australian guidelines for losing or maintaining weight promote dietary modification, physical activity and a combination of these ${ }^{(42)}$. Promotion of these strategies may have resulted in the high proportion of participants in the present study engaging in these behaviours.
The less-frequently adopted behaviours (such as diet pills, laxatives, diuretics) may be less sustainable strategies on a long-term basis, and may involve adopting entirely new behaviours rather than modifying existing behaviours. Furthermore, these strategies may be less effective and more harmful for health and may have greater cost implications compared with the more popular strategies ${ }^{(8,16)}$. Interestingly, consulting health professionals for weight control was reported by only a small proportion of participants (4-10\%). This may be due to a number of factors, including cost of consulting these professionals, participants' perceived ability to self-manage weight control and preference for strategies that may be perceived as resulting in faster or easier weight loss (e.g. fad diets, some liquid diet supplements, commercial weight-loss programmes).

\section{Socio-economic differences in weight-control strategies}

Consistent with international $^{(9,43)}$ and Australian studies ${ }^{(11)}$, our study showed that there were socio-economic differences in WCB, despite greater prevalence of overweight and obesity among the disadvantaged group ${ }^{(4,5)}$. A possible rationale for this paradox is that socio-economic groups may differ in their attitudes and beliefs towards lifestyle, health and diseases. Previous studies suggest that socioeconomic differences in healthy lifestyle are associated with differences in attitudes towards health; lower socioeconomic groups are more likely to possess stronger beliefs in the influence of chance on health, have lower levels of health consciousness and think less about their future ${ }^{(44)}$. Others have found that disadvantaged groups do not perceive poor dietary intake to play an important role in the development of overweight or obesity ${ }^{(45)}$. Hence, lower socio-economic groups may be less likely to adopt a healthy lifestyle or engage in behaviours to control their weight when there are minimal perceived benefits or associations with improved health outcomes.

Furthermore, among those who engaged in weight control, lower socio-economic groups were less likely to report engaging in exercise for weight control compared 
Table 5 OR and $95 \% \mathrm{Cl}$ for socio-economic differences in barriers to weight control ${ }^{\star}$

The odds of 'strongly agree or agree'

Educational level

Trying to lose weight

Requires serious commitment

Requires a lot of motivation

Is difficult

Requires support from my partner

Requires a lot of food and exercise knowledge

Is difficult to achieve when you are dining out

Is not a high priority when I have other things to do

Is time-consuming

Requires support from other people around you

Is restrictive

Requires you to eat differently from people in your household

Is expensive

Is not difficult at all

Requires a lot of cooking skills

\begin{tabular}{|c|c|c|c|c|c|c|}
\hline \multicolumn{2}{|c|}{ Secondary school or lower } & \multicolumn{2}{|c|}{ Certificate } & \multicolumn{2}{|c|}{ Diploma } & \multirow{2}{*}{$\begin{array}{c}\text { Bachelor's degree } \\
\text { or higher (ref.) }\end{array}$} \\
\hline OR & $95 \% \mathrm{Cl}$ & OR & $95 \% \mathrm{Cl}$ & OR & $95 \% \mathrm{Cl}$ & \\
\hline 0.61 & $0.33,1.12$ & 0.83 & $0.38,1 \cdot 83$ & 1.09 & $0.43,2.71$ & $1 \cdot 00$ \\
\hline 1.03 & $0.63,1.68$ & 0.91 & $0.49,1.68$ & 1.21 & $0.59,2.47$ & 1.00 \\
\hline $1 \cdot 24$ & $0.84,1 \cdot 83$ & 0.83 & $0.51,1.35$ & 1.07 & $0.63,1.83$ & 1.00 \\
\hline $1 \cdot 15$ & $0.80,1.66$ & 0.84 & $0.53,1.33$ & $1 \cdot 24$ & $0.73,2.09$ & 1.00 \\
\hline $1 \cdot 14$ & $0.82,1.60$ & 1.07 & $0.70,1.62$ & $1 \cdot 12$ & $0.70,1 \cdot 79$ & 1.00 \\
\hline $0 \cdot 76$ & $0.54,1.07$ & 0.62 & $0.40,0.96$ & 0.77 & $0.48,1.24$ & $1 \cdot 00$ \\
\hline $1 \cdot 14$ & $0.82,1.60$ & 0.95 & $0.62,1.46$ & 0.82 & $0.52,1.29$ & 1.00 \\
\hline $1 \cdot 27$ & $0.91,1.77$ & $1 \cdot 35$ & $0.88,2.07$ & 1.01 & $0.63,1.62$ & 1.00 \\
\hline $1 \cdot 23$ & $0.88,1 \cdot 71$ & 0.96 & $0.63,1.46$ & $1 \cdot 12$ & $0.70,1 \cdot 78$ & 1.00 \\
\hline 1.03 & $0.74,1.45$ & $1 \cdot 06$ & $0.69,1.64$ & 0.71 & $0.44,1 \cdot 15$ & 1.00 \\
\hline $1 \cdot 13$ & $0.80,1.57$ & $1 \cdot 28$ & $0.84,1.94$ & $1 \cdot 22$ & $0.76,1.96$ & 1.00 \\
\hline 1.80 & $1 \cdot 23,2 \cdot 65$ & 1.47 & $0.91,2.38$ & $1 \cdot 35$ & $0.78,2.32$ & 1.00 \\
\hline $1 \cdot 25$ & $0.84,1.86$ & $1 \cdot 14$ & $0.69,1.88$ & 0.69 & $0.38,1.26$ & 1.00 \\
\hline $1 \cdot 48$ & $0.98,2 \cdot 21$ & 0.87 & $0.50,1.50$ & $1 \cdot 41$ & $0 \cdot 81,2 \cdot 46$ & 1.00 \\
\hline
\end{tabular}

\begin{tabular}{|c|c|c|c|c|c|c|c|}
\hline & \multirow{2}{*}{\multicolumn{2}{|c|}{ 1st quartile }} & \multirow{2}{*}{\multicolumn{2}{|c|}{ 2nd quartile }} & \multirow{2}{*}{\multicolumn{2}{|c|}{ 3rd quartile }} & \\
\hline & & & & & & & \multirow[b]{2}{*}{ 4th quartile (ref.) } \\
\hline & OR & $95 \% \mathrm{Cl}$ & OR & $95 \% \mathrm{Cl}$ & OR & $95 \% \mathrm{Cl}$ & \\
\hline \multicolumn{8}{|l|}{ Trying to lose weight } \\
\hline Requires serious commitment & 0.77 & $0 \cdot 35,1 \cdot 70$ & $0 \cdot 84$ & $0 \cdot 39,1 \cdot 81$ & 0.98 & $0 \cdot 46,2 \cdot 11$ & 1.00 \\
\hline Requires a lot of motivation & 0.94 & $0.50,1 \cdot 77$ & $1 \cdot 49$ & $0 \cdot 78,2 \cdot 82$ & $1 \cdot 15$ & $0 \cdot 64,2 \cdot 06$ & $1 \cdot 00$ \\
\hline Is difficult & 1.03 & $0 \cdot 61,1 \cdot 75$ & 0.81 & $0.50,1 \cdot 32$ & 0.87 & $0.54,1.39$ & $1 \cdot 00$ \\
\hline Requires support from my partner & 0.99 & $0.61,1.60$ & $1 \cdot 11$ & $0 \cdot 70,1 \cdot 76$ & 1.05 & $0.68,1.63$ & $1 \cdot 00$ \\
\hline Requires a lot of food and exercise knowledge & $1 \cdot 38$ & $0 \cdot 89,2 \cdot 14$ & $1 \cdot 30$ & $0.86,1.95$ & $1 \cdot 03$ & $0 \cdot 70,1 \cdot 53$ & $1 \cdot 00$ \\
\hline Is difficult to achieve when you are dining out & $1 \cdot 16$ & $0 \cdot 75,1 \cdot 81$ & $1 \cdot 28$ & $0.85,1.95$ & 1.50 & $1 \cdot 00,2 \cdot 24$ & 1.00 \\
\hline Is not a high priority when I have other things to do & $1 \cdot 76$ & $1 \cdot 12,2 \cdot 75$ & 0.96 & $0.64,1.45$ & 0.91 & $0.61,1 \cdot 35$ & $1 \cdot 00$ \\
\hline Is time-consuming & 1.45 & $0.93,2 \cdot 26$ & $1 \cdot 44$ & $0 \cdot 95,2 \cdot 17$ & $1 \cdot 11$ & $0 \cdot 75,1.65$ & $1 \cdot 00$ \\
\hline Requires support from other people around you & $1 \cdot 21$ & $0 \cdot 78,1 \cdot 87$ & $1 \cdot 10$ & $0.73,1.66$ & 0.88 & $0.59,1.31$ & 1.00 \\
\hline Is restrictive & $1 \cdot 37$ & $0 \cdot 88,2 \cdot 15$ & $1 \cdot 15$ & $0.76,1.74$ & $1 \cdot 21$ & $0.81,1 \cdot 81$ & $1 \cdot 00$ \\
\hline Requires you to eat differently from people in your household & $1 \cdot 74$ & $1 \cdot 12,2 \cdot 71$ & $1 \cdot 77$ & $1 \cdot 17,2 \cdot 69$ & $1 \cdot 15$ & $0 \cdot 76,1 \cdot 72$ & 1.00 \\
\hline Is expensive & 2.45 & $1 \cdot 49,4.04$ & $2 \cdot 27$ & $1 \cdot 41,3.64$ & 1.35 & $0 \cdot 84,2 \cdot 17$ & 1.00 \\
\hline Is not difficult at all & $1 \cdot 15$ & $0.67,1.97$ & $1 \cdot 51$ & $0.93,2.47$ & 1.00 & $0.61,1.63$ & $1 \cdot 00$ \\
\hline Requires a lot of cooking skills & 1.51 & $0.91,2.50$ & $1 \cdot 14$ & $0 \cdot 70,1 \cdot 86$ & $0 \cdot 85$ & $0.51,1.39$ & $1 \cdot 00$ \\
\hline
\end{tabular}

Ref., reference category.

“Multinomial logistic regression analyses were adjusted for gender, country of birth and BMI. The reference group for barriers to weight control was 'strongly disagree or disagree'. Those who responded 'Don't know' were included in the analyses as a separate group not reported in the current table. The analytical sample excludes those with missing data for country of birth, BMI, education, income and weight-control behaviours in the past

tParticipants who responded 'Don't know' or 'Don't want to answer' were included in the analyses; however, results are not shown in the current table. 
with their more-advantaged counterparts. Although existing studies have also found socio-economic differences in adopting exercise strategies ${ }^{(9,16)}$, these studies did not examine specific types of exercise strategies. The present study showed that disadvantaged groups were less likely to engage in vigorous or moderate physical activities for weight control compared with their socio-economically advantaged counterparts. In general, the literature also suggests that lower socio-economic groups are less likely to engage in moderate or vigorous physical activity ${ }^{(46)}$. However, lower socio-economic groups are more likely to engage in occupational physical activity, which may result in them being less likely to engage in leisure-time physical activity to reduce or maintain their weight ${ }^{(47)}$. Socioeconomic differences in physical activity level or exercise strategies for weight control may be partly due to the inequalities in morbidity associated with overweight or obesity among lower socio-economic groups ${ }^{(6,48)}$. Furthermore, these groups may have more limited exposure, fewer activity-promoting cognitions, may perceive fewer anticipated benefits of physical activity, experience less social support or may have inconvenient access to facilities. The costs of these activities may also be a barrier ${ }^{(20)}$. Consequently, lower socio-economic groups may be more inclined to target their sedentary behaviours, such as time spent sitting, compared with advantaged groups.

No socio-economic differences were seen for dietary strategies for weight control. This may be because of a number of factors. In contrast to physical activity, which may be a planned behaviour, consumption of food is integrated into everyone's lifestyle and may therefore be easier to modify, including for those in lower socioeconomic groups. Furthermore, as diet comprises a range of food and nutrient intakes, which differ in their capacity to contribute to weight loss or maintenance ${ }^{(30)}$, there may be more scope to manipulate dietary factors compared with physical activity in order to achieve these goals.

\section{Socio-economic differences in barriers to weight control}

Findings suggest that lower socio-economic groups are more likely to perceive a number of barriers to weight control compared with their more-advantaged counterparts. Previous studies examining perceived barriers to general healthy dietary intakes and physical activity among disadvantaged groups have reported similar barriers, including cost and availability of healthy foods ${ }^{(18,19)}$, lack of time because of work commitments ${ }^{(19)}$, inconvenience of access to facilities $^{(20)}$ and poorer nutritional knowledge ${ }^{(49)}$. Hence, these reported perceived barriers for undertaking health-promoting diet and physical activity among lower socio-economic groups may play a role in the differences observed for perceptions of barriers to weight loss.

Different measures of SEP may represent different pathways by which socio-economically disadvantaged groups perceive barriers to weight control. Education represents an individual's acquired knowledge and ability to analyse health-related information ${ }^{(35)}$. We found that less-educated groups were more likely to perceive that weight control was expensive and required cooking skills. This may be because these groups have lower nutritional knowledge and less healthy cooking skills. However, income represents the material resources of an individual more accurately - the amount of money they have available to spend on health and on prevention of ill health ${ }^{(35)}$. Hence, lower-income groups may perceive weight control as a less important priority because of competing constraints on material resources.

\section{Strengths and limitations}

The present study achieved a high response (69.8\%) and the measures of WCB and barriers to losing weight were shown to be reliable according to the test-retest reliability of these items. The sociodemographic and health characteristics of Brisbane residents in the study region did not differ markedly from those of the remaining Australian population ${ }^{(50)}$. A limitation of the present study is that there may be response bias and/or social desirability bias among individuals who are sensitive to questions regarding their WCB. The sample under-represented less-educated groups; therefore, the magnitude of the socio-economic differences reported in the study may underestimate that of the population. Furthermore, participants may underreport socially undesirable behaviours, such as the use of diet pills, vomiting and fasting, and over-report more 'acceptable' behaviours that are consistent with the recommendations to maintain a healthy weight ${ }^{(42)}$. Perceived barriers to weight control may have been overreported as most barrier items were phrased negatively in the present study (e.g. 'Trying to lose weight is difficult'). Given that socio-economically disadvantaged groups are more likely to be overweight or obese, the negative phrasing of these items may have resulted in reporting bias, potentially increasing the magnitude of the socioeconomic inequalities in the perceived barriers reported in the present study. Another limitation of the study is the use of self-reported height and weight. Lower socioeconomic groups are more likely to underestimate their BMI when using self-reported height and weight ${ }^{(51)}$. Thus, the present study may underestimate the true prevalence of overweight and obesity and the magnitude of these inequalities. However, studies have shown that self-reported height and weight are relatively valid measures at a population level ${ }^{(52,53)}$. Furthermore, a common limitation of postal questionnaires and self-completed surveys is the under-representation of socio-economically disadvantaged groups ${ }^{(54,55)}$. Those excluded from the analytical sample because of missing data had lower educational and income levels, which may have further attenuated the magnitude of the socio-economic differences found. The sampling frame of the present study was obtained from the Australian electoral roll, which excludes non-Australian citizens. The Australian migration 
policy selects migrants on the basis of their occupation and health characteristics ${ }^{(6)}$; therefore, migrants tend to have health behaviours and health outcomes that are the same as or better than Australian citizens. Their exclusion in the present study is unlikely to underestimate the socioeconomic inequalities in weight status and the potential determinants of these inequalities. Finally, the present study had a cross-sectional study design; hence, we were unable to ascertain the duration of weight-control strategies that individuals engaged themselves in.

In conclusion, the present study showed that there were marked socio-economic differences in WCB and in several perceived barriers to weight control. Therefore, targeting the types of weight-control strategies used and perceived barriers to weight control may be important in health promotion strategies that address socio-economic inequalities in weight status and inequalities in weightrelated health outcomes.

\section{Conclusions and implications of the study}

Despite overweight or obesity being more prevalent among socio-economically disadvantaged adults in this age group, lower socio-economic groups are less likely to undertake measures to control their weight and are more likely to perceive a number of barriers to weight control, compared with their more-advantaged counterparts. These differences in barriers to weight control may contribute to socio-economically disadvantaged groups being less likely to engage in weight control and, consequently, to have greater likelihood of being overweight or obese. The present study suggests that interventions and public health initiatives targeting overweight or obesity among socioeconomically disadvantaged groups should encourage weight control and more specifically the engagement of exercise strategies, including moderate and vigorous physical activity. Furthermore, addressing socio-economic differences in actual or perceived barriers to weight control in clinical interventions and at the upstream level (e.g. providing living environments that are conducive to physical activity, making healthy foods affordable to lower socioeconomic groups) may promote WCB among this group. In conclusion, engaging in WCB, the types of weight-control strategies used and real or perceived barriers to weight control may need to be addressed in health promotion strategies that target socio-economic inequalities in weight status and inequalities in weight-related health outcomes. To further understand socio-economic differences in weight control, future research should examine determinants or reasons for weight control and whether these differ by SEP.

\section{Acknowledgements}

The present study was funded by the Queensland University of Technology. The authors have no conflict of interest to declare. J.S. and K.G. drafted the initial manuscript and conducted the analyses. All authors contributed to the design of the project and to interpretation of the data, provided feedback on drafts and read and approved the final manuscript.

\section{References}

1. Haslam D \& James P (2005) Obesity. Lancet 366, 1197-1209.

2. Flegal K, Carroll M, Kuczmarski R et al. (1998) Overweight and obesity in the United States: prevalence and trends, 1960-1994. Int J Obes Relat Metab Disord 22, 39-47.

3. Kelly T, Yang W, Chen C et al. (2008) Global burden of obesity in 2005 and projections to 2030. Int J Obes (Lond) 32, $1431-1437$.

4. McLaren L (2007) Socioeconomic status and obesity. Epidemiol Rev 29, 29-48.

5. Sobal J \& Stunkard A (1989) Socioeconomic status and obesity: a review of the literature. Psychol Bull 105, 260-275.

6. Turrell G, Stanley L, de Looper M et al. (2006) Health Inequalities in Australia: Morbidity, Health Behaviours, Risk Factors and Health Service Use. Canberra: Queensland University of Technology and the Australian Institute of Health and Welfare.

7. Ball K, Mishra G \& Crawford D (2002) Which aspects of socioeconomic status are related to obesity among men and women? Int J Obes Relat Metab Disord 26, 559-565.

8. Williams L, Germov J \& Young A (2007) Preventing weight gain: a population cohort study of the nature and effectiveness of mid-age women's weight control practices. Int J Obes (Lond) 31, 978-986.

9. Jeffery R \& French S (1996) Socioeconomic status and weight control practices among 20- to 45-year-old women. Am J Public Health 86, 1005-1010.

10. Wardle J \& Griffith J (2001) Socioeconomic status and weight control practices in British adults. J Epidemiol Community Health 55, 185-190.

11. Paxton S, Sculthorpe A \& Gibbons K (1994) Weight loss strategies and beliefs in high and low socioeconomic areas of Melbourne. Aust N Z J Public Health 18, 412-417.

12. Kruger J, Galuska D, Serdula M et al. (2004) Attempting to lose weight specific practices among US adults. Am J Prev Med 26, 402-406.

13. Weiss E, Galuska D, Khan L et al. (2006) Weight-control practices among US adults, 2001-2002. Am J Prev Med 31, $18-24$.

14. Timperio A, Cameron-Smith D, Burns C et al. (2000) Physical activity beliefs and behaviours among adults attempting weight control. Int J Obes Relat Metab Disord 24, 81-87.

15. Serdula M, Williamson $\mathrm{D}$, Anda $\mathrm{R}$ et al. (1994) Weight control practices in adults: results of a multistate telephone survey. Am J Public Health 84, 1821-1824.

16. Tsai A, Wadden T, Pillitteri J et al. (2009) Disparities by ethnicity and socioeconomic status in the use of weight loss treatments. J Natl Med Assoc 101, 62-70.

17. French S, Jeffery R, Story M et al. (1998) Perceived barriers to and incentives for participation in a weight-loss program among low-income women in WIC. J Am Diet Assoc 98, $79-81$.

18. Giskes K, van Lenthe F, Brug J et al. (2007) Socioeconomic inequalities in food purchasing: the contribution of respondent-perceived and actual (objectively measured) price and availability of foods. Prev Med 45, 41-48.

19. Inglis V, Ball K \& Crawford D (2005) Why do women of low socioeconomic status have poorer dietary behaviours than women of higher socioeconomic status? A qualitative exploration. Appetite 45, 334-343. 
20. Burton N, Turrell G \& Oldenburg B (2003) Participation in recreational physical activity: why do socioeconomic groups differ? Health Educ Behav 30, 225-244.

21. Dunstan D, Zimmet P, Welborn T et al. (2001) Diabesity and Associated Disorders in Australia - 2000: The Accelerating Epidemic. Melbourne: International Diabetes Institute.

22. Ball K, Crawford D, Ireland P et al. (2003) Patterns and demographic predictors of 5-year weight change in a multiethnic cohort of men and women in Australia. Public Health Nutr 6, 269-280.

23. Hadden W (1996) The use of educational attainment as an indicator of socioeconomic position. Am J Public Health 86, $1525-1526$.

24. Australian Electoral Commission (2008) Electoral roll frequently asked questions. http://www.aec.gov.au/FAQs/ Electoral_Roll.htm (accessed March 2009).

25. Dillman D (1972) Increasing mail questionnaire response in large samples of the general public. Public Opin Q 36, 254-257.

26. Brennan M (1992) Techniques for improving mail survey response rate. Market Bull 3, 24.

27. Greer T, Chuchinprakarn N \& Seshadri S (2000) Likelihood of participating in mail survey research. Ind Market Manage 29, 97-109.

28. Erwin W \& Wheelright L (2002) Improving mail survey response rates through the use of a monetary incentive. $J$ Mental Health Counseling 24, 247-255.

29. Landis J \& Koch G (1977) The measurement of observer agreement for categorical data. Biometrics 33, 159-174.

30. National Health and Medical Research Council (2003) Clinical Practice Guidelines for the Management of Overweight and Obesity in Adults. Australia: NHMRC.

31. Baker International Diabetes Institute (2006) AusDiab Questionnaires. http://www.bakeridi.edu/ausdiab/publication/ (accessed April 2011).

32. Centers for Disease Control and Prevention (2010) National Health and Nutrition Examination Survey: 2005-2006 Questionnaire File. http://www.cdc.gov/nchs/nhanes/nhanes20052006/quex05_06.htm (accessed February 2010).

33. Feinstein A \& Cicchetti D (1990) High agreement but low kappa: I. The problems of two paradoxes. J Clin Epidemiol 43, 543-549.

34. Mak H, Yau K \& Chan B (2004) Prevalence-adjusted biasadjusted kappa values as addiitonal indicators to measure observer agreement. Radiology 232, 302-303.

35. Galobardes B, Shaw M, Lawlor D et al. (2006) Indicators of socioeconomic position (part 1). J Epidemiol Community Health 60, 7-12.

36. Sobal J (1991) Obesity and socioeconomic status: a framework for examining relationships between physical and social variables. Med Anthropol 13, 231-247.

37. Galobardes B, Morabia A \& Bernstein M (2000) The differential effect of education and occupation on body mass and overweight in a sample of working people of the general population. Ann Epidemiol 10, 532-537.

38. Australian Bureau of Statistics (2007) 6537.0-Government Benefits, Taxes and Household Income, Australia, 2003-04.
Canberra: Australian Bureau of Statistics; available at http://www.abs.gov.au/AUSSTATS/abs@.nsf/Latestproducts/ 6537.0Appendix22003-04

39. Australian Bureau of Statistics (2010) CDataOnline. http:// www.abs.gov.au/CDataOnline (accessed March 2010).

40. Timperio A, Cameron-Smith D, Burns C et al. (2000) The public's response to the obesity epidemic in Australia: weight concerns and weight control practices of men and women. Public Health Nutr 4, 417-424.

41. World Health Organization (2000) Obesity: Preventing and Managing the Global Epidemic. Report of a WHO Consultation on Obesity. WHO Technical Report Series no. 894. Geneva: WHO.

42. National Health and Medical Research Council (2003) Dietary Guidelines for Australian Adults. Australia: Commonwealth of Australia.

43. Story M, French S, Resnick M et al. (1995) Ethnic/racial and socioeconomic differences in dieting behaviors and body image perceptions in adolescents. Int J Eat Disord 18, $173-179$.

44. Wardle J \& Steptoe A (2003) Socioeconomic differences in attitudes and beliefs about healthy lifestyles. I Epidemiol Community Health 57, 440-443.

45. Dammann K \& Smith C (2009) Factors affecting lowincome women's food choices and the perceived impact of dietary intake and socioeconomic status on their health and weight. J Nutr Educ Behav 41, 242-253.

46. Gidlow C, Johnston L, Crone D et al. (2006) A systematic review of the relationship between socio-economic position and physical activity. Health Educ J 65, 338-367.

47. Popham F \& Mitchell R (2007) Relation of employment status to socioeconomic position and physical activity types. Prev Med 45, 182-188.

48. Brown A \& Siahpush M (2007) Risk factors for overweight and obesity: results from the 2001 National Health Survey. $J$ R Inst Public Health 121, 603-613.

49. Parmenter K, Waller J \& Wardle J (2000) Demographic variation in nutrition knowledge in England. Health Educ Res 15, 163-174.

50. Australian Institute of Health and Welfare (2008) Australia's Health Series. Catalogue no. AUS 99. Canberra: AIHW.

51. McLennan W (1995) How Australians Measure Up. Canberra: Australian Bureau of Statistics.

52. Tehard B, Van Lielre M, Com Nougue C et al. (2002) Anthropometric measurements and body sihouette of women: validity and perceptions. J Am Diet Assoc 102, $1779-1784$.

53. Waters A (1993) Assessment of Self-Reported Height and Weight and Their Use in the Determination of Body Mass Index. Canberra: AIHW.

54. Drivsholm T, Eplov L, Davidsen M et al. (2006) Representativeness in population-based studies: a detailed description of non-response in a Danish cohort study. Scand J Public Health 34, 623-631.

55. van Loon A, Tijhuis M, Picavet $\mathrm{H}$ et al. (2003) Survey non-response in the Netherlands: effects on prevalence estimates and associations. Ann Epidemiol 13, 105-110. 